\title{
ALFABETIZAÇÃO E LETRAMENTO APLICADOS AOS DADOS DA COVID-19: EXEMPLOS PRÁTICOS PARAA DOCÊNCIA EM NÍVEL BÁSICO ${ }^{1}$
}

\author{
LITERACY, LETTERING APPLIED TO COVID-19 DATA: \\ PRACTICAL EXAMPLES FOR TEACHING AT BASIC LEVEL
}

\section{Carina Petsch $^{2}$, Natália Lampert Batista ${ }^{3}$, Maurício Rizzatti ${ }^{4}$, Tascieli Feltrin $^{5}$ e Dayane Oliveira Verneque ${ }^{6}$}

\section{RESUMO}

O presente artigo imbricado nas questões emergentes dos efeitos da pandemia, provocados pela COVID-19, na educação e nas práticas escolares tem por objetivos: primeiramente, apresentar plataformas de dados da COVID-19 que fomentem a alfabetização e o letramento cartográfico; e, apresentar propostas de atividades e discussões para as aulas de Geografia que auxiliem aos educadores na oferta de um trabalho educacional que auxilie à população na compreensão dos dados sobre a pandemia. A importância da discussão dos dados da COVID-19 se dá em função da necessidade de os alunos compreenderem como a Geografia pode explicar vários padrões de dispersão do vírus e a cartografia escolar deve ser utilizada voltada para a interpretação dos mapas e construção do conceito espacial. As propostas apresentadas podem tornar significativa a interpretação da evolução da pandemia, bem como aliam os conhecimentos geográficos e da cartografia escolar com o uso de ferramentas tecnológicas que podem motivar e estimular professores e estudantes na promoção de práticas pedagógicas remotas em contextos possíveis.

Palavras-chave: Ensino, Educação, Geografia, Pandemia.

\section{ABSTRACT}

The present article intertwined with the issues emerging from the effects of the pandemic, caused by COVID-19, on education and school practices aims to: first, present COVID-19 data platforms that promote literacy and cartographic literacy; and, to present proposals for activities and discussions for Geography classes that assist educators in offering educational work that helps the population in understanding data about the pandemic. The importance of discussing COVID-19 data is due to the need for students to understand how Geography can explain various patterns of virus dispersion and school cartography should be used aimed at interpreting maps and building the spatial concept. The proposals presented can make the evolution of the pandemic significant, as well as combine geographic knowledge and school cartography with the use of technological tools that can motivate and stimulate teachers and students in the promotion of remote pedagogical practices in possible contexts.

Keywords: Teaching, Education, Geography, Pandemic.

\footnotetext{
${ }^{1}$ Trabalho de Ensino e Pesquisa - UFSM.

${ }^{2}$ Docente do Departamento de Geociências - Universidade Federal de Santa Maria. E-mail: carinapetsch@gmail.com

${ }^{3}$ Pós doutoranda do Programa de Pós-Graduação em Geografia da Universidade Federal de Santa Maria. E-mail: natilbatista3@ gmail.com

${ }^{4}$ Doutorando do Programa de Pós-Graduação em Geografia da Universidade Federal de Santa Maria. E-mail: geo.mauricio. rizzatti@gmail.com

${ }^{5}$ Doutoranda em Educação na Universidade Federal de Santa Maria. E-mail: tascifeltrin@gmail.com

${ }^{6}$ Graduanda em Geografia na Universidade Federal de Santa Maria - E-mail: dayaneowerneck@gmail.com
} 


\section{INTRODUÇÃO}

O momento atual, imposto pela disseminação da COVID-19, aponta crises e incertezas que assolam os setores econômicos, políticos, de saúde e, também, educacional. No início de março de 2020, como uma medida de prevenção a propagação da COVID-19, o isolamento social foi adotado pelo governo brasileiro e as aulas suspensas na educação básica e ensino superior. Sobre a dinâmica desse novo tempo em educação, Santana Filho (2020) aponta que:

A docência e a educação escolar estão abaladas. A pandemia, ao nos isolar uns dos outros, estudantes, professores, pedagogos, gestores públicos e privados, abala a dinâmica da escola: seu sentido baseado na convivência e compartilhamento de ideias e saberes, na transmissão de conteúdos consolidados e conduzida por práticas seculares se encontra revirado (SANTANA FILHO, 2020, p. 5).

É um momento em que muito tem se discutido sobre quais as melhores estratégias para dar continuidade ao semestre ou ao ano letivo. Alguns estados e instituições optaram por ensino remoto emergencialmente, há também instituições que discutem modelos híbridos, ou, que aguardam a retomada presencial das atividades. Espaços como lives, simpósios on-line e materiais publicados trazem vários pesquisadores para debater sobre quais as melhores estratégias a serem adotadas para garantir o aprendizado dos alunos.

Entre tantos questionamentos chamamos a atenção para o papel da Geografia e, em especial, da Cartografia. Os mapas, nesse contexto, estão presentes no cotidiano das pessoas, através dos mapeamentos de casos confirmados da COVID-19, óbitos e incidência de casos por 100 mil habitantes; sendo veiculados em mídias sociais, em jornais e programas de televisão. Os estudantes, possivelmente, passaram a ter um maior contato com essa espacialização dos dados. Nesse sentido, importa pensar se esta exposição aos mapas significa que eles consigam de fato fazer uma leitura e compreender o que foi representado. Sobre esta questão Passini (2012) salienta que:

\footnotetext{
Podemos considerar como dever da escola proporcionar as aprendizagens das noções espaciais ao desenvolvimento das potencialidades de ler o espaço e sua representação como meios de desenvolver a autonomia. $\mathrm{O}$ aluno integra-se no espaço sociocultural ao fazer leituras do espaço onde mora, circula, estuda e brinca. O conhecimento construído de forma espontânea, com sua vivência, avança por meio de trabalhos de sistematização que a elaboração de mapas e gráficos exige (PASSINI, 2012, p. 42).
}

Para compreender todas as informações representadas em um mapa, é necessária que haja a alfabetização e o letramento cartográfico (PISSINATI; ARCHELA, 2007). Devemos nos preocupar em discuti-los para melhorar a interpretação do espaço vivido, a partir das representações cartográficas. O objetivo desse artigo, a partir do exposto, concentra-se em apresentar plataformas de dados da COVID-19 para fomentar a alfabetização e o letramento cartográfico e propostas de atividades e discussões para as aulas de Geografia. 


\section{PLATAFORMAS DE DADOS DISPONÍVEIS COM DADOS DA COVID-19}

O trabalho se organiza de maneira a apresentar, a seguir, os dados disponíveis nas plataformas oficiais, a nível estadual, relativos à COVID-19 e, na sequência, discute-se propostas de atividades para o desenvolvimento da alfabetização ${ }^{7}$ e do letramento ${ }^{8}$ cartográfico. Recomendamos a leitura do material divulgado pelo Laboratório de Estudos e Pesquisas em Educação Geográfica ${ }^{9}$, que se dedica a mostrar alguns aspectos da Cartografia Temática, voltada ao entendimento dos dados da COVID-19.

Com o objetivo de disponibilizar para os professores as plataformas de dados de monitoramento da dispersão da COVID-19 pelo Brasil foi organizado o Quadro 1, mostrando o endereço dos links, os dados disponíveis e o método de representação cartográfica.

Quadro 1 - Plataformas oficiais dos estados, dados disponibilizados sobre a COVID-19 e o método de espacialização.

\begin{tabular}{|c|c|c|c|}
\hline $\mathbf{U F}$ & ENDEREÇO ON-LINE & DADOS DISPONÍVEIS MAPEADOS & MÉTODO \\
\hline $\mathrm{AC}$ & http://covid19.ac.gov.br/ & Casos Confirmados por municípios & Coroplético \\
\hline $\mathrm{AL}$ & http://www.alagoascontraocoronavirus.al.gov.br/ & Casos Confirmados por municípios & Coroplético \\
\hline AP & http://painel.corona.ap.gov.br/ & $\begin{array}{l}\text { Casos Confirmados para municípios e bairros } \\
\text { (Macapá e Santana) }\end{array}$ & $\begin{array}{c}\text { Círculos } \\
\text { Proporcionais }\end{array}$ \\
\hline $\mathrm{AM}$ & http://www.saude.am.gov.br/painel/corona/ & $\begin{array}{l}\text { Incidência de COVID-19 por municípios e } \\
\text { bairros (Manaus) }\end{array}$ & Coroplético \\
\hline $\mathrm{BA}$ & $\begin{array}{l}\text { http://www.saude.ba.gov.br/temasdesaude/corona- } \\
\text { virus/notas-tecnicas-e-boletins-epidemiologicos- } \\
\text {-covid-19/ }\end{array}$ & Distribuição espacial de casos confirmados & Coroplético \\
\hline $\mathrm{CE}$ & $\begin{array}{l}\text { https://indicadores.integrasus.saude.ce.gov.br/ } \\
\text { indicadores/indicadores-coronavirus/coronavirus- } \\
\text {-ceara }\end{array}$ & $\begin{array}{l}\text { Incidência dos casos confirmados acumulada e } \\
\text { últimos } 15 \text { dias, segundo município de residên- } \\
\text { cia; Taxa de mortalidade por COVID-19 acu- } \\
\text { mulada e últimos } 15 \text { dias, segundo municípios } \\
\text { de residência; Distribuição espaco-temporal dos } \\
\text { casos confirmados de COVID-19 por polígonos. }\end{array}$ & Coropléticos \\
\hline DF & $\begin{array}{l}\text { https://covid19.ssp.df.gov.br/extensions/covid19/ } \\
\text { covid19.html\#/ }\end{array}$ & $\begin{array}{l}\text { Mapa de casos confirmados por regiões admi- } \\
\text { nistrativas em valores absolutos e incidência } \\
\text { para } 100 \text { mil habitantes. }\end{array}$ & Coroplético \\
\hline ES & https://coronavirus.es.gov.br/painel-covid-19-es & $\begin{array}{l}\text { Mapa de Calor (Kernel) com informações a } \\
\text { nível municipal }\end{array}$ & Densidade \\
\hline GO & $\begin{array}{l}\text { https://extranet.saude.go.gov.br/pentaho/api/repos/ } \\
\text { :coronavirus:paineis:painel.wcdf/generatedContent }\end{array}$ & Casos Confirmados e Suspeitos & Corocromático \\
\hline MG & http://www.saude.mt.gov.br/informe/584 & $\begin{array}{l}\text { Secretaria de Saúde estadual não produziu } \\
\text { mapas até então, mas possui dados estatísticos. }\end{array}$ & - \\
\hline
\end{tabular}

${ }^{2}$ De acordo com Simielli (2007a), para desenvolver a alfabetização cartográfica nos alunos, deve-se trabalhar noções de visão oblíqua e a visão vertical, a imagem tridimensional e a imagem bidimensional, o alfabeto cartográfico (ponto, linha e área), a construção da noção de legenda, a proporção e a escala, a lateralidade, referências e orientação espacial.

${ }^{3}$ Segundo Richter (2017, p. 291), o “[...] Letramento Cartográfico se estabelece na ação e no processo de desenvolver o uso do mapa para as práticas sociais dos indivíduos, de entender o mapa como um instrumento que possibilita compreender nossas ações e vivências cotidianas. [...] Para isso é pertinente que o professor integre o mapa em diferentes atividades e propostas tornando esta linguagem mais viva e presente na vida do aluno. Representar seus caminhos, suas leituras espaciais, correlacionar diferentes formas de mapear com os conteúdos geográficos ensinados em aula são atividades que podem contribuir neste trabalho". (RICHTER, 2017, p. 291).

${ }^{4}$ Disponível em: https://lepeg.iesa.ufg.br/p/32483-cartografia-da-covid-19. Acesso em: 12 jul. 2020. 


\begin{tabular}{|c|c|c|c|}
\hline MS & http://mais.saude.ms.gov.br/hub/ & $\begin{array}{l}\text { Taxa Diária de Isolamento e Incidência de } \\
\text { COVID-19 por municípios }\end{array}$ & Coroplético \\
\hline MA & $\begin{array}{l}\text { http://www.saude.ma.gov.br/painel-atualizado- } \\
\text {-covid-19/ }\end{array}$ & $\begin{array}{l}\text { Casos Confirmados por município, Mapa de } \\
\text { Calor para a Grande São Luiz e evolução da } \\
\text { COVID-19. }\end{array}$ & $\begin{array}{l}\text { Pontos, } \\
\text { Densidade e } \\
\text { Diagramas. }\end{array}$ \\
\hline MG & $\begin{array}{l}\text { http://coronavirus.saude.mg.gov.br/painel-de- } \\
\text {-monitoramento }\end{array}$ & $\begin{array}{l}\text { Mapa de Calor (Kernel) para Casos } \\
\text { Confirmados. }\end{array}$ & Densidade \\
\hline PA & $\begin{array}{l}\text { https://www.covid-19.pa.gov.br/public/dashboard/ } \\
\text { 41777953-93bf-4a46-b9c2-3cf4ccefb3c9 }\end{array}$ & $\begin{array}{l}\text { Casos Confirmados por municípios e } \mathrm{N}^{\circ} \text { por } \\
\text { Regional de Saúde. }\end{array}$ & Coroplético \\
\hline PB & $\begin{array}{l}\text { https://superset.plataformatarget.com.br/superset/ } \\
\text { dashboard/55/ }\end{array}$ & Casos Confirmados por municípios & $\begin{array}{c}\text { Círculos } \\
\text { Proporcionais }\end{array}$ \\
\hline PR & $\begin{array}{l}\text { http://www.saude.pr.gov.br/Pagina/Coronavirus- } \\
\text {-COVID-19 }\end{array}$ & $\begin{array}{l}\text { Informe Epidemiológico: Municípios com } \\
\text { Casos Confirmados; Municípios com óbitos } \\
\text { por COVID-19 }\end{array}$ & Coroplético \\
\hline $\mathrm{PE}$ & https://dados.seplag.pe.gov.br/apps/corona.html\#mapas & $\begin{array}{l}\text { Casos confirmados, com sintomas de Síndrome } \\
\text { respiratória aguda, casos suspeitos, óbitos e } \\
\text { recuperações }\end{array}$ & $\begin{array}{l}\text { Mapa de } \\
\text { círculos } \\
\text { proporcionais }\end{array}$ \\
\hline PI & $\begin{array}{l}\text { https://datastudio.google.com/u/0/reporting/ } \\
\text { a6dc07e9-4161-4b5a-9f2a-6f9be486e8f9/page/2itOB }\end{array}$ & $\begin{array}{l}\text { Casos Confirmados e óbitos por residência; } \\
\text { Mapas de Barreiras Sanitárias, Isolamento } \\
\text { Social e Cobertura Terrestre SAMU }\end{array}$ & $\begin{array}{l}\text { Coroplético e } \\
\text { Pontos }\end{array}$ \\
\hline $\mathrm{RN}$ & https://covid19.saude.rn.gov.br/\#o-rn & $\begin{array}{l}\text { Casos Confirmados, suspeitos e óbitos por } \\
\text { municípios e Regiões de Saúde }\end{array}$ & Coroplético \\
\hline $\mathrm{RS}$ & http://ti.saude.rs.gov.br/covid19/ & $\begin{array}{l}\text { Casos Confirmados e taxa de incidência para } \\
100 \text { mil habitantes por municípios }\end{array}$ & $\begin{array}{c}\text { Pontos e } \\
\text { Coroplético }\end{array}$ \\
\hline RJ & $\begin{array}{l}\text { http://painel.saude.rj.gov.br/monitoramento/ } \\
\text { covid19.html\# }\end{array}$ & $\begin{array}{l}\text { Casos Confirmados por municípios e Regiões } \\
\text { de Saúde }\end{array}$ & Coroplético \\
\hline RO & http://covid19.sesau.ro.gov.br/ & Casos Confirmados por municípios & Coroplético \\
\hline $\mathrm{RR}$ & $\begin{array}{l}\text { https://roraimacontraocorona.rr.gov.br/winner/ } \\
\text { public/mapa.xhtml }\end{array}$ & Municípios com Casos Confirmados & Corocromático \\
\hline $\mathrm{SC}$ & http://www.coronavirus.sc.gov.br/boletins/ & $\begin{array}{l}\text { Boletim Epidemiológico: Distribuição de casos } \\
\text { por município; Distribuição de óbitos por mu- } \\
\text { nicípio; Casos confirmados por Macrorregião } \\
\text { de saúde; Óbitos por Macrorregião de saúde }\end{array}$ & $\begin{array}{l}\text { Círculos } \\
\text { Proporcionais e } \\
\text { Coroplético }\end{array}$ \\
\hline SP & https://www.seade.gov.br/coronavirus/ & $\begin{array}{l}\text { Casos Confirmados e Taxa de Isolamento por } \\
\text { municípios }\end{array}$ & Coroplético \\
\hline SE & https://todoscontraocorona.net.br/ & $\begin{array}{l}\text { Casos Confirmados, óbitos, letalidade e isola- } \\
\text { mento social de COVID-19 por municípios }\end{array}$ & Coroplético \\
\hline TO & http://integra.saude.to.gov.br/covid19 & $\begin{array}{l}\text { Casos Confirmados, suspeitos, óbitos, mortali- } \\
\text { dade e divisão por gênero por municípios }\end{array}$ & Coroplético \\
\hline
\end{tabular}

Fonte: Organizado pelos Autores, 2020.

\section{ALFABETIZAÇÃO E LETRAMENTO CARTOGRÁFICO APLICADOS À COVID-19}

Nesta seção, apresenta-se as propostas de discussões passíveis de serem feitas em aulas de Geografia do ensino básico visando a alfabetização e o letramento cartográfico dos alunos. A importância da discussão dos dados da COVID-19 se dá em função da necessidade de os alunos compreenderem como a Geografia pode explicar vários padrões de dispersão do vírus, e a cartografia escolar deve ser utilizada voltada para a interpretação dos mapas e construção do conceito espacial. Dessa forma, Almeida (2011) define que a cartografia escolar é a interface entre a cartografia, a educação e 
a ciência geográfica, sendo assim os conceitos cartográficos são elementos fundamentais para o processo de ensino-aprendizagem da Geografia.

\section{TIPOS DE VISÃO}

Para iniciar a discussão sobre os tipos de visão, devemos salientar que segundo Simielli (2007b) a maioria das pessoas, o que inclui os alunos da educação básica, está acostumada com a visão horizontal e a oblíqua. Dificilmente teremos condição de fazer uma análise de um espaço na visão vertical, salvo quando analisamos imagens de satélite e fotografias aéreas ou se viajarmos de avião ou balão. Romano (2007) define a visão vertical como aquela em que a direção do olhar é perpendicular ao objeto que queremos observar. A Figura 1 apresenta a exemplificação dos tipos de visão.

Figura 1 - Três tipos de visão aplicados a situações que envolvem o distanciamento necessário durante a pandemia da COVID-19.

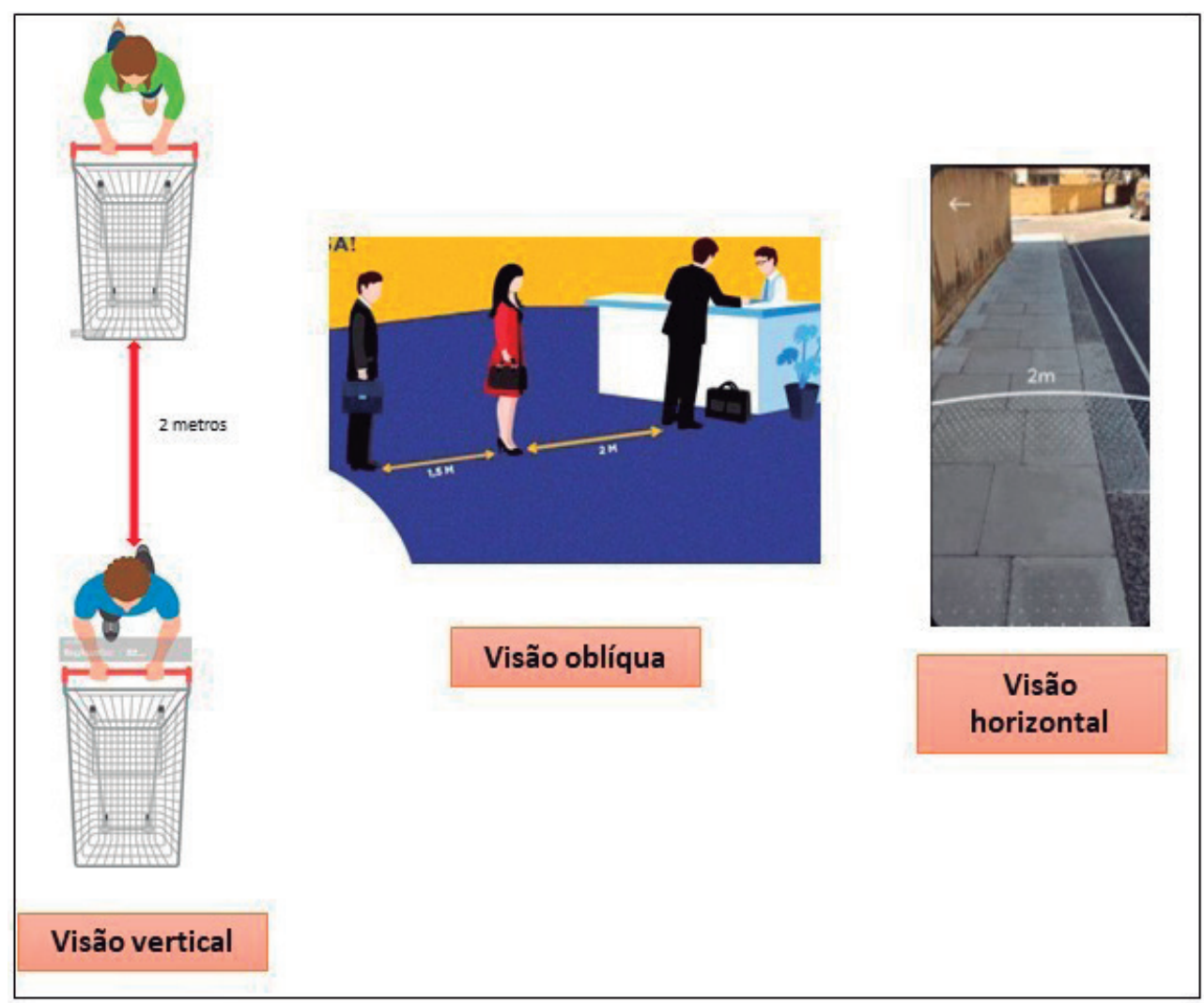

Fonte: Visão vertical: https://www.gettyimages.pt/; Visão oblíqua: https://bit.ly/38xuynH; Visão horizontal: https://sodar.withgoogle.com/. Acesso em: 12 jul. 2020.

Aplicando essa discussão para a COVID-19, segundo as normas da Organização Pan-Americana da Saúde (PAN, 2020), devemos manter distanciamento de no mínimo 1 metro de outros indivíduos já que o contágio pode ocorrer ao respirar gotículas de uma pessoa infectada. Mas como essa informação contribui na visão espacial dos alunos? Ao se fazer uma busca pelo Google podemos encontrar vários materiais que fazem desenhos esquemáticos de como deve ser feito esse distanciamento, respeitando um 
raio de 1 a 2 metros de demais indivíduos. Alguns materiais mostram como isso deve ser feito, utilizando a visão vertical, outros com uma visão oblíqua e alguns ainda com a visão horizontal. Considerando a noção espacial da criança (PASSINI, 1994), desenhos esquemáticos que mostrem a visão horizontal são mais facilmente compreendidos. A visão vertical exige maior abstração, já que não é aquela que diariamente temos no nosso ambiente de vivência.

Nesse sentido, propomos aqui a utilização de um aplicativo de realidade aumentada (RA), desenvolvida pela Google, chamado SODAR ${ }^{10}$. Ele cria uma realidade aumentada de 2 metros de raio ao redor do celular (Figura 01) e permite uma visão horizontal do distanciamento necessário em relação a outras pessoas. Esses aplicativos permitem a interação do aluno com o ambiente, mantendo a visão horizontal e a construção da noção de espaço. Callai (2005) complementa que as atividades envolvendo cartografia devam ser apoiadas em dados concretos e reais, nesse caso, situações reais em que os alunos devem praticar o isolamento social.

\section{TIPOS DE IMAGEM}

Comumente, nas plataformas estaduais de monitoramento da COVID-19 (Quadro 1) e na plataforma oficial do Governo Brasileiro ${ }^{11}$, os dados são representados em mapas bidimensionais. Pissinati e Archela (2007) refletem que o mapa é uma representação plana, com uma visão vertical e que a maioria das pessoas não está acostumada com essa realidade.

A forma mais usada de representação de dados em três dimensões é a maquete e em ambiente on-line é recorrente o uso do Google Earth. Simieli (2007) retrata que a maquete permite a visualização de dados topográficos e importantes correlações podem ser feitas a partir dessa representação. Contudo, além da topografia, vários dados permitem a espacialização utilizando um eixo z, com altura exagerada para melhorar a visualização. As plataformas interativas que permitem manipulação de dados e, além disso, os dados representados sobre o Globo Terrestre, são possivelmente de mais fácil entendimento pelos alunos.

Aqui propomos o uso de duas plataformas tridimensionais. O Corona3D ${ }^{12}$ (Figura 2A) é uma simulação interativa em 3D do total de casos da COVID-19. As colunas verticais são proporcionais ao número de confirmados de COVID-19 nos países. Os alunos conseguem facilmente fazer a associação do tamanho da coluna com o número de casos, sem recorrer a uma legenda, o que também tem um ponto negativo. O aluno possui uma noção comparativa entre os países, porém não consegue calcular os valores de casos confirmados.

\footnotetext{
${ }^{5}$ Disponível em: https://sodar.withgoogle.com/. Acesso em: 12 jul. 2020.

${ }^{6}$ Disponível em: https://covid.saude.gov.br/. Acesso em: 12 jul. 2020.

${ }^{7}$ Disponível em: https://corona3d.github.io/counties. Acesso em: 12 jul. 2020.
} 
A plataforma COVID-19 3D ${ }^{13}$ (Figura 2B) obtém seus dados das atualizações em tempo real do Worldometer $^{14}$ e das séries temporais do CSSEGIS e Data/COVID-19. Neste aplicativo, assim que o usuário clica no país de interesse, os limites do território são destacados e uma janela mostrando os dados fica disponível. Além de casos confirmados, mortes e recuperados, o aplicativo fornece a bandeira do país e a população total.

O aplicativo COVID-19 3D permite, assim como o Corona3D, o acompanhamento dos dados em uma série temporal desde 22 de janeiro de 2020. Martinelli (2005) ressalta a importância das representações dinâmicas e que estas deveriam estar em destaque na Cartografia, visto que a realidade é mutante e fluída. Adentrando nessa discussão, os dados da COVID-19 são altamente mutáveis. Todos os dias, após a divulgação dos dados das Secretárias de Saúde dos estados brasileiros, verificamos novos dados, cenários e atualizações nos mapas. As tecnologias precisam suprir essa demanda rápida de atualização.

Figura 2 - Plataformas interativas tridimensionais mostrando os dados da COVID-19 em todos os países.

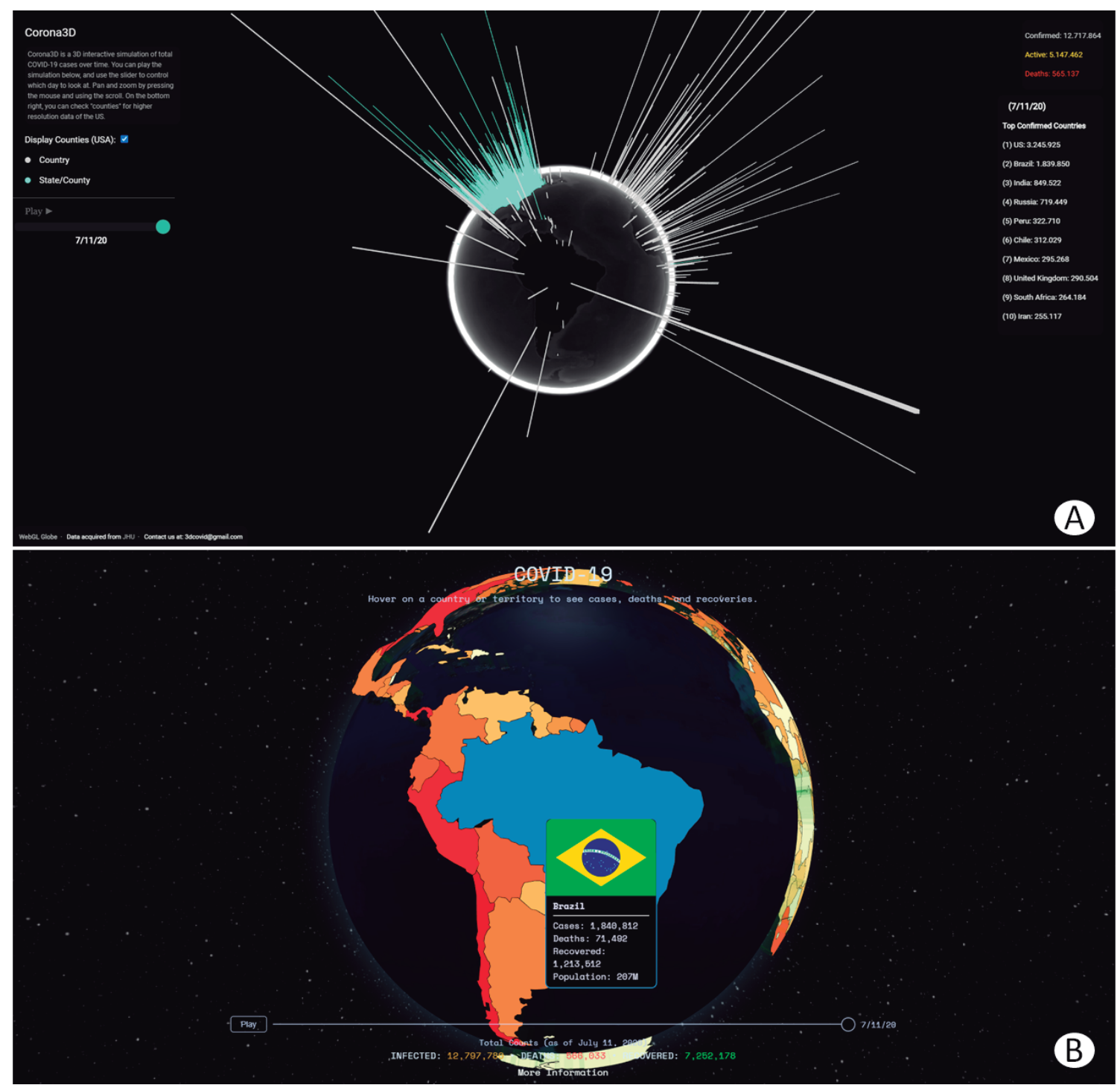

Fonte: https://corona3d.github.io/counties e https://covid3d.live/. Acesso em: 12 jul. 2020.

\footnotetext{
${ }^{8}$ Disponível em: https://covid3d.live/. Acesso em: 12 jul. 2020.

${ }^{9}$ Disponível em: https://www.worldometers.info/coronavirus/. Acesso em: 12 jul. 2020.
} 
Outro produto cartográfico que pode ser incluído em aulas de Geografia, no atual contexto de pandemia, refere-se à densidade demográfica. No modelo tridimensional elaborado pelo IBGE (Figura 3), a densidade demográfica é representada pela altura das colunas. É possível observar a concentração da população brasileira na zona costeira e mal distribuída pelo Brasil.

A densidade demográfica é um dado importante a ser considerado dentro do padrão de dispersão da COVID-19 pelo Brasil, ainda que outros dados, como a mobilidade também seja fundamental para se entender os eixos de propagação da doença. Segundo Coelho et al. (2020) o Brasil apresenta forte heterogeneidade espacial em termos de demografia, idade distribuição, acesso à saúde pública e índices de pobreza. Ainda segundo o mesmo autor, essa heterogeneidade deve afetar o impacto da pandemia da COVID-19 em todo o país, uma vez que são dados relacionados à transmissibilidade, letalidade e vulnerabilidade. Sendo assim, o modelo tridimensional facilita a compreensão do dado de densidade demográfica no país e sua distribuição desigual, permitindo discussões de como a COVID-19 se espalhou de forma discrepante pelos municípios. Enquanto grandes capitais, com maior densidade populacional, registraram seu primeiro caso de COVID-19 em março, cidades interioranas e com menor densidade podem ainda não ter registrado nenhum caso.

Figura 3 - Modelo tridimensional da densidade demográfica do Brasil.

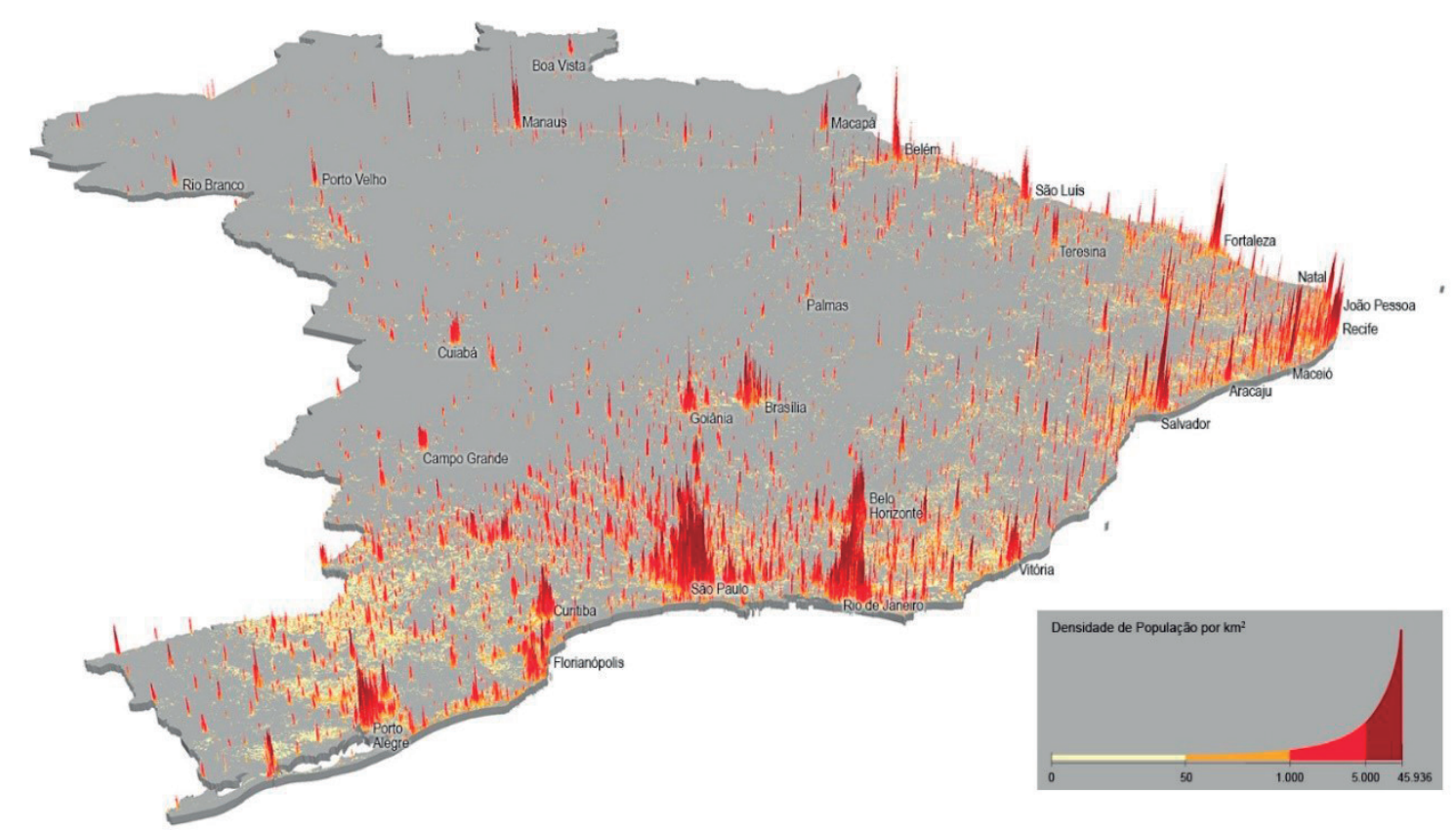

Fonte: https://mapasinterativos.ibge.gov.br/atlas_ge/brasil1por1.html. Acesso em: 12 jul. 2020.

Para visualização da densidade populacional em todo o planeta há o projeto Human Terrain (Figura 4), que utiliza colunas exageradas verticalmente para representação dos dados de cidades. A plataforma se baseia em dados da Global Human Settlement Layer. As cidades com alta densidade populacional possuem picos maiores e quando há uma área suburbana ocorre uma lenta descida de colunas em volta da coluna maior. A plataforma também não permite acesso aos dados brutos de 
população, contudo possui uma ferramenta comparando a população de 1990 a 2015. Sendo assim, permite discussões que vão além da COVID-19, como a migração, crescimento ou redução populacional nas cidades e fenômenos de conurbação nesse intervalo de tempo.

Figura 4 - Representação populacional de algumas cidades da região sul do país.

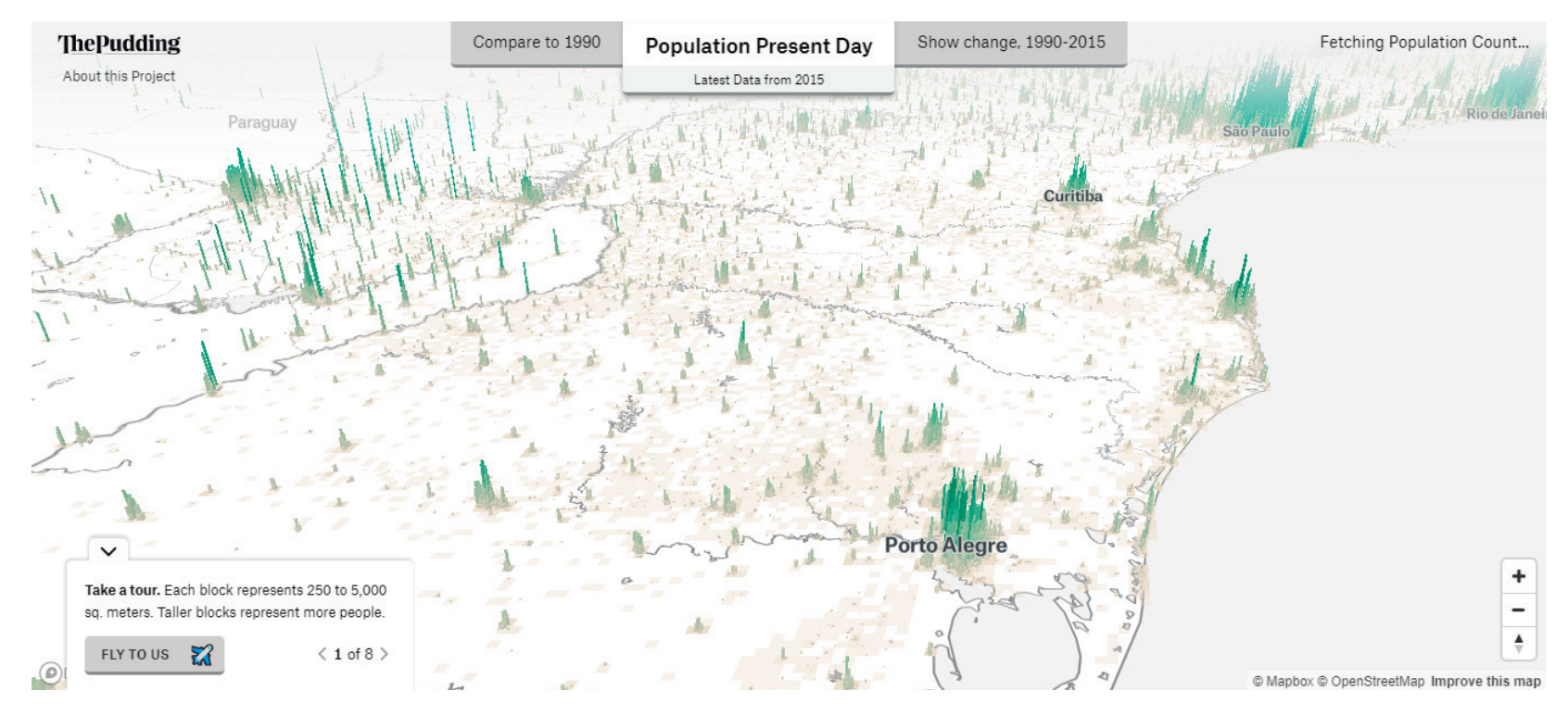

Fonte: https://pudding.cool/2018/10/city_3d/?utm_medium=website\&utm_source=archdaily.com.br. Acesso em: 12 jul. 2020.

\section{LEGENDA E ALFABETO CARTOGRÁFICO}

No momento em que o professor propõe uma atividade envolvendo a elaboração ou interpretação de um mapa, segundo Simielli (2007b), o aluno mapeador consciente e o aluno leitor crítico precisa refletir como determinado dado irá se transformar numa representação gráfica. Simielli (2007a) aponta que isso ocorrerá por meio da escolha de uma variável visual da Semiologia Gráfica (tamanho, valor, forma, orientação, granulação e cor) e com os elementos de linhas, pontos e áreas, definidos como o alfabeto cartográfico, que objetos do mundo real se tornarão representações no plano bidimensional. Segundo um exemplo da própria autora: "a montanha (ponto), a estrada (linha) e a lagoa (área)" (SIMIELLI 2007a, p. 100).

Para a composição da legenda é preciso compreender que a sua composição se dá pela associação simbólica, icônica ou indexical. A primeira constitui-se de elementos convencionados que irão representar elementos no mapa, por exemplo, um ponto pode representar uma cidade. O segundo, refere-se a desenhos que representam o elemento mapeado, por exemplo, o desenho de uma árvore a representa em seu local. E o terceiro, por meio de relações estabelecidas entre o signo e o elemento mapeado, ou seja, a utilização do recorte da área urbana (máscara da área urbana) na legenda como sua representação pode ser associada indexalmente com a sua constituição política. Todos esses elementos dependerão da temática mapeada e da escala de representação. O mesmo elemento pode ser representado de formas diferentes em escalas maiores ou menores, de acordo com a riqueza de 
detalhes apresentada. Esses diferentes elementos que irão ser utilizados no mapa para representação, constituem o alfabeto cartográfico, isto é, todos os elementos cartografados, obrigatoriamente, serão representados por pontos, linhas ou áreas.

Por isso, pensar sobre a legenda é essencial, pois se o aluno não compreende o que o mapa com dados da COVID-19 está representando, não ocorre uma efetiva interpretação. A maioria dos mapas disponibilizados pelos órgãos oficiais dos estados e do governo brasileiro espacializam em mapas coropléticos e círculos proporcionais as cidades com maior número de casos ou taxa de incidência por 100 mil habitantes.

Um dos exemplos que trazemos e que pode ser utilizado nas aulas de Geografia é a plataforma $\mathrm{ICAO}^{15}$ (Coronavirus 3DFX dispersion Daily Update), que utiliza-se de uma legenda simbólica (convencionada), a qual permite a visualização de dados em três dimensões, referentes ao número de casos, proporciona a manipulação do Globo, inserindo o horário local e apresenta uma ferramenta de medição. O aplicativo permite ainda discussões sobre rotação da terra, fusos horários e aspectos de escala.

Figura 5 - Plataforma ICAO - Coronavirus 3DFX dispersion Daily Update mostrando diferentes símbolos atribuídos aos dados representados.

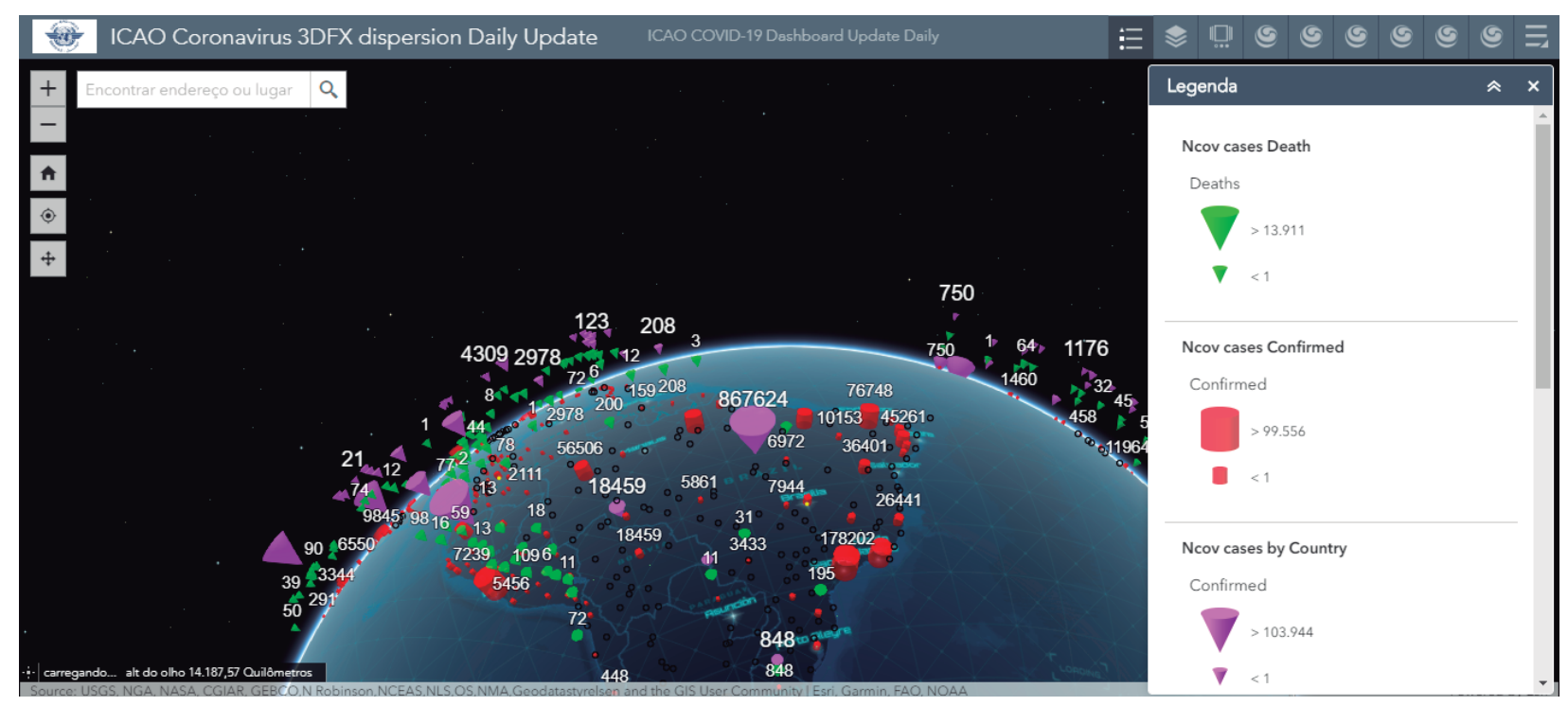

Fonte: https://bit.ly/3njt58v. Acesso em: 12 jul. 2020.

\section{ESCALA E PROPORÇÃO}

Pissinati e Archela (2007) definem a escala como a proporção usada entre o objeto representado e o elemento real. Sendo assim, na medida em que representamos áreas menores teremos maiores detalhes, pois teremos uma redução menor do objeto em questão. Nesse sentido, quando os alunos interagem com um mapa no papel, a escala do mapa é fixa, ou seja, o mapa está impresso e não é possível obter um nível de detalhamento maior. Porém, as plataformas interativas que representam a espacialização dos dados da COVID-19 para todo o Brasil possuem a capacidade de alterarmos a

\footnotetext{
${ }^{15} \mathrm{https}$ ://icao.maps.arcgis.com/apps/webappviewer3d/index.html?id=d9d3f8fa9a23425c8f0889baab626186
} 
escala representada com grande facilidade. $\mathrm{O}$ aluno pode ver qual o cenário de todo o Brasil e pode dar zoom até seu município, ampliando, assim, sua escala de visualização.

Como já discutimos acima, a representação quantitativa dos dados da COVID-19 é feita geralmente utilizando o modo de implantação pontual e a variável visual tamanho, através de círculos proporcionais ou mapas de pontos. Segundo a plataforma oficial do governo brasileiro ${ }^{16}$, a cidade de São Paulo possui 93.448 casos confirmados no dia 16 de junho de 2020, enquanto vários municípios possuem somente 1 caso. Isso causa um grande desafio para a representação dos dados, já que possuem uma variação de 93.447 casos e os círculos devem ser proporcionais ao número de casos. Na figura 6, mostramos que o professor pode frisar isso com os alunos em suas aulas de Geografia, como a escala implica na visualização destes dados.

A primeira plataforma se refere a dados da COVID-19 para o estado do RS (Figura 6A). A plataforma utiliza implementação pontual atrelada à variação visual de cor, além de números indicando o valor de casos confirmados. Na medida que vamos aumentando o zoom, alterando a escala e os detalhes apresentados (Figura 6B), é possível verificar que muitos destes círculos são agrupamentos de vários municípios. No exemplo abaixo, Frederico Westphalen apresenta 1154 casos, e quando ocorre a aplicação do zoom, esse valor se apresenta em 245. Sendo assim é possível observar que há casos em vários municípios a sua volta, que na escala em nível estadual eram contabilizados juntos com o círculo que representa somente Frederico Westphalen. Assim, os círculos não se sobrepõem e permitem a visualização do mapa base, contudo não é possível visualizar os valores de cada município quando reduzimos todo o estado do RS para caber em nossa tela de computador ou celular.

A segunda plataforma foi criada pela Universidade Federal do Rio Grande do $\mathrm{Su}^{17}$ e espacializa dados da COVID-19 para todo o Brasil. O método utilizado é o de círculos proporcionais, porém sem uso da variável visual cor ou de números indicando os dados. Aqui o aluno pode perceber que temos uma legenda com círculos de tamanhos fixos e que quando visualiza-se todo o Brasil, reduzido a tela do computador ou celular, há uma enorme sobreposição de círculos, inviabilizando o cálculo do quantitativo de casos por municípios, mas permitindo uma visão geral da distribuição da doença (Figura 6C). Na medida em que vamos dando zoom, mais detalhes nos são apresentados, assim, quando recorremos a legenda, é possível através do tamanho dos círculos saber quantos casos confirmados temos em cada município (Figura 6D). Diferentemente da plataforma do estado (RS), não ocorre a junção de vários círculos em um só na escala de menor detalhe (todo o estado).

Um exercício que pode ser proposto é descobrir qual a distância que municípios do interior, sem infraestrutura adequada para o atendimento da COVID-19, ficam de uma cidade polo, que possui essa possibilidade de atender os indivíduos suspeitos. Essa discussão é interessante na medida em que muitas pessoas precisam percorrer grandes distâncias para ter acesso a um hospital, mostrando assim

\footnotetext{
${ }^{16}$ Disponível em: https://covid.saude.gov.br/ Acesso em: 12 jul. 2020.

${ }^{17}$ Disponível em: https://www.ufrgs.br/sig/mapas/covid19-brasil/ Acesso em: 12 jul. 2020.
} 
as desigualdades sociais e econômicas no Brasil. Conforme Almeida (2001) com o uso dos mapas os alunos poderão trabalhar escalas locais, regionais e nacionais, possibilitando uma visão reflexiva da realidade em que está inserido.

\section{LATERALIDADE E ORIENTAÇÃO ESPACIAL}

As noções de lateralidade e orientação são fundamentais para o entendimento e localização nos mapas. Simielli (2007b) ressalta que muitas vezes o problema do aluno com a orientação espacial está em conceitos anteriores não desenvolvidos, nas noções de lateralidade e referências. Sugerimos que seja desenvolvida a noção de lateralidade e orientação com os alunos de acordo com diferentes níveis de escala, começando por quadras próximas da escola e bairros da cidade, já que são de maior vivência do aluno, posteriormente trabalhar com a localização espacial dos municípios vizinhos e por fim, partir para escalas de estado e País.

Nas plataformas que permitem interação com todo o Brasi1 $1^{18}$, o aluno pode começar identificando quais são os municípios vizinhos, qual o município próximo com maior número de casos, posteriormente ampliar essa discussão para qual a orientação do seu município de moradia em relação às cidades brasileiras com maior número de casos. Nas plataformas de dados que permitem a visualização da evolução dos casos em escala temporal ${ }^{19}$, é interessante debater qual a orientação da China em relação ao Brasil, posteriormente indagar os alunos sobre a orientação dos eixos de dispersão que a COVID-19 seguiu temporalmente, sendo que uma primeira onda de casos ocorreu na Europa e então um segundo eixo para a América.

A atividade de orientação espacial pode consistir também na localização do município em que o aluno mora e discussão sobre a região de influência em que está inserido, por exemplo se a família recorre a outros municípios para serviços de saúde e de comércio. Esses deslocamentos, ainda que tenham apresentado redução ${ }^{20}$ durante o período de isolamento social, são frequentes, e possivelmente contribuíram na dispersão da COVID-19 para municípios com menor população.

\footnotetext{
${ }^{18}$ Disponível em: https://www.ufrgs.br/sig/mapas/covid19-brasil/ e https://covid.saude.gov.br/ Acesso em: 12 jul. 2020.

19 Disponível em: https://corona3d.github.io/counties. Acesso em: 12 jul. 2020. Disponível em: https://covid3d.live/. Acesso em: 12 jul. 2020.

20 https://agenciadenoticias.ibge.gov.br/agencia-noticias/2012-agencia-de-noticias/noticias/27750-pesquisa-mostra-como-populacao-se-deslocava-para-compras-antes-da-pandemia
} 
Figura 6 - Mapa interativo do Painel Coronavírus RS (A e B) e COVID-19 Brasil UFRGS (C e D).
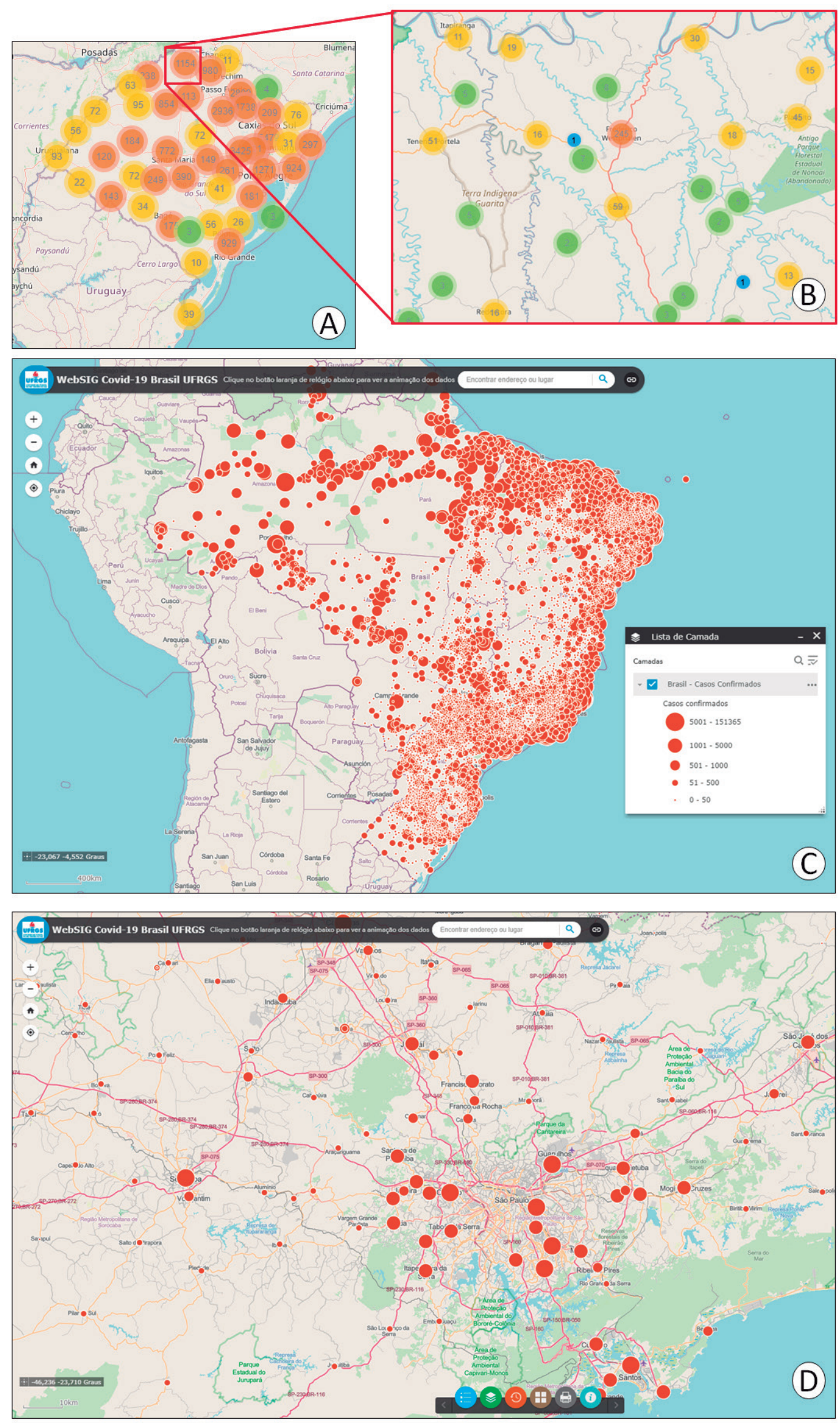

Fonte: http://ti.saude.rs.gov.br/covid19/ e https://www.ufrgs.br/sig/mapas/covid19-brasil/. Acesso em 12 de jul. 2020. 
Com base nas plataformas apresentadas e nas discussões referentes à cartografia escolar, destacamos que as propostas têm potencialidade de colaborar com o desenvolvimento da alfabetização e do letramento cartográfico frente aos alunos em ensino emergencial, pois levam à discussão de uma temática atual e que desperta curiosidade, por impactar na vida dos estudantes e da sociedade como um todo, utilizando-se de diferentes formas de interações e de representação cartográfica. Todavia, esse tipo de proposta prescinde da mediação, mesmo que a distância, do docente de Geografia como orientador da interpretação e da leitura desses dados.

Assim, o conjunto de plataformas apresentadas têm potencialidade para o planejamento de aulas, mesmo em contexto emergencial, porém menosprezar os contextos possíveis: os estudantes e professores possuem acesso à internet e equipamentos que os permitem utilizar tais ferramentas? Em situações com resposta positiva, facilmente as propostas podem ser implementas e potencializar a aprendizagem. Entretanto, se a resposta for negativa, tais propostas se tornam inviáveis. É necessário que tenhamos em mente tais extremos e que saibamos que isso não pode ser desconsiderado. É claro que não podemos privar os estudantes que têm acesso às ferramentas, de aulas que as incluam, mas necessitamos ser críticos e compreender que esse contexto expõe e amplia as desigualdades sociais e de acesso a oportunidades didático-pedagógicas em contexto de excepcionalidade.

Por outro lado, devemos destacar que a situação de ensino remoto vigente se torna um desafio, também, aos docentes, pois muitos não têm domínio tecnológico para uso de tais ferramentas. Assim, a breve apresentação delas serve como difusão de possibilidades. Contudo, para o uso eficiente e correto delas, caberá ao usuário estudá-las e adaptá-las ao seu contexto de atuação. Com essa adaptação recomendada não pretende ser uma "receita pedagógica", pois respeita-se a individualidade de cada contexto escolar, mas apenas um subsídio à pesquisa de ferramentas a serem utilizadas pelos professores caso eles desejem utilizar tais estratégias pedagógicas.

Dessa forma, nos propomos a apresentar possibilidades pedagógicas que auxiliem nos processos de alfabetização e letramento cartográfico, levando aos estudantes e docentes a utilizarem as ferramentas e interpretá-las, sem perder de vista a importância da mediação docente neste processo de interpretação de dados e de construção de saberes, bem como a necessidade de humanização das práticas pedagógicas. Ao discutir dados da COVID-19 buscamos entender o momento histórico que estamos vivendo e, assim, buscar novas posturas, novas estratégias e novas maneiras e ser e de estar no mundo.

\section{CONSIDERAÇÕES FINAIS}

São infinitas as possibilidades de se trabalhar com a interpretação de mapas, dentro do contexto de dispersão da COVID-19. Para que os alunos da educação básica possam interpretar todas as informações 
constantes nos mapas que circulam e as plataformas que reúnem dados sobre o Brasil, ou sobre cada estado, precisamos pensar em desenvolver atividades que fomentem a alfabetização cartográfica e o letramento cartográfico. Na lógica do ensino remoto emergencial, elaborar atividades para fomentar alunos leitores críticos contribui na interpretação do espaço e no desenvolvimento do raciocínio geográfico.

As práticas de ensino desenvolvidas no ensino remoto emergencial são desafiadoras para todos os professores que precisam adaptar vários conteúdos para um modelo on-line, além de lidar com a pressão da sociedade e dos pais para dar continuidade ao semestre, somado as dúvidas dos alunos. O contexto de desigualdade social apresentado no território brasileiro imprime diversos cenários nas escolas brasileiras, e salientamos que muitos alunos não possuem acesso à internet o que inviabiliza a aplicação das atividades aqui propostas. Ressaltamos também que o presente artigo apresenta uma série de possibilidades pedagógicas, e que estas devem ser repensadas e adaptadas para os diversos contextos que o docente se depara.

Acreditamos que a correta interpretação dos dados, pela população, disponibilizados sobre o avanço da COVID-19 no Brasil seja de fundamental importância para seu combate e para a diminuição da circulação de fake news sobre a doença. Investir no aprendizado de uma leitura e interpretação correta de tais dados pode contribuir para que tenhamos cidadãos conscientes, que não serão agenciados por discursos desinformados; que poderão, por exemplo, a partir de dados sobre a distância existente entre um leito COVID-19 e seu bairro ou cidade acompanhar e cobrar investimentos dos órgãos responsáveis; pode-se, também, pensar a longo prazo na prevenção a novas epidemias, a partir de uma conscientização sobre os locais de maior aglomeração e trânsito de pessoas em relação à oferta de serviços de saúde.

\section{REFERÊNCIAS}

AGUIAR, V. T. Navegar, com mapas, é bem mais preciso! In: ALMEIDA, R. D. de (Org.). Novos rumos da cartografia escolar: currículo, linguagem e tecnologia. São Paulo: Contexto, 2011, p. 37-56.

ALMEIDA, R. D. de. Cartografia Escolar. São Paulo: Contexto, 2011.

ALMEIDA, R. D. de. (Org). Do Desenho ao Mapa: iniciação cartográfica na escola. São Paulo: Contexto, 2001.

ARCHELA, R. S.; THÉRY, H. Orientação metodológica para construção e leitura de mapas temáticos. Confins - Revista Franco-brasileira de Geografia. n. 3, p. 2-21, 2008.

CALLAI, H. C. Aprendendo a ler o mundo: a geografia nos anos iniciais do ensino fundamental. Caderno Cedes, v. 25, n. 66, p. 227-247, 2005. 
COElHO, F. C.; LANA, R. M.; CRUZ, O. G.; VILlELA, D.; BASTOS, L. S.; PASTORE Y PIONTTI, A.; DAVIS, J. T.; VESPIGNANI, A.; CODECO, C.; GOMES, M. F. C. Assessing the Potential Impact of COVID-19 in Brazil: Mobility, Morbidity and the Burden on the Health Care System. SRRN - PRE PRINT. 2020. DOI: http://dx.doi.org/10.2139/ssrn.3559609

MARTINELLI, M. Cartografia dinâmica: tempo e espaço nos mapas. GEOUSP - Espaço e Tempo, n. 18, p. 53-66, 2005.

PAN - ORGANIZAÇÃO PAN-AMERICANA DA SAÚDE. Folha informativa - Covid-19. Disponível em: https://bit.ly/36v2PBk. Acesso em: 27 Maio 2020.

PASSINI, E. Y. Alfabetização cartográfica e o livro didático: uma análise crítica. Belo Horizonte: Lê, 1994.

PASSINI, E. Y. Alfabetização cartográfica e a aprendizagem em Geografia. Colaboração Romão Passini.1 ed. - São Paulo: Cortez, 2012.

PISSINATI, M. C.; ARCHELA, R. S. Fundamentos da Alfabetização Cartográfica no Ensino de Geografia. Geografia. v. 16, p. 169-95, 2007.

RICHTER, D. A linguagem cartográfica no ensino de Geografia. Revista Brasileira de Educação em Geografia, v. 7, p. 277-300, 2017.

ROMANO, S. M. M. Alfabetização Cartográfica: A Construção do Conceito de Visão Vertical e a Formação de Professores. In: CASTELLAR, S. (Org). Educação Geográfica - teorias e práticas docentes. São Paulo: Contexto, 2007.

SANTANA FILHO, M. M. Educação Geográfica, Docência e o Contexto da Pandemia COVID-19. Revista Tamoios, ano 16, n. 1, Especial COVID-19. p. 3-15, 2020.

SIMIELLI, M. E. R. Cartografia no ensino fundamental e médio. In: CARLOS, A. F. A. (org). A Geografia na Sala de Aula. 8. ed. São Paulo: Contexto, 2007a.

SIMIELLI, M. E. R. O mapa como meio de comunicação e a alfabetização cartográfica. In: ALMEIDA, R. D. de (Org.). Cartografia escolar. São Paulo: Contexto, 2007b. 